https://helda.helsinki.fi

\title{
The joint contribution of cardiovascular disease and socioeconomic status to disability retirement : A register linkage study
}

\section{Virtanen, Marianna}

2017-03-01

Virtanen, M , Lallukka , T , Ervasti , J , Rahkonen , O , Lahelma , E , Pentti , J , Pietiläinen , O , Vahtera , J \& Kivimaki , M 2017 , ' The joint contribution of cardiovascular disease and socioeconomic status to disability retirement : A register linkage study ', International Journal of Cardiology , vol. 230 , pp. 222-227 . https://doi.org/10.1016/j.ijcard.2016.12.166

http://hdl.handle.net/10138/234774

https://doi.org/10.1016/j.ijcard.2016.12.166

publishedVersion

Downloaded from Helda, University of Helsinki institutional repository.

This is an electronic reprint of the original article.

This reprint may differ from the original in pagination and typographic detail.

Please cite the original version. 


\title{
The joint contribution of cardiovascular disease and socioeconomic status to disability retirement: A register linkage study
}

\author{
Marianna Virtanen ${ }^{\mathrm{a}, *, 1}$, Tea Lallukka ${ }^{\mathrm{a}, \mathrm{b}, 1}$, Jenni Ervasti ${ }^{\mathrm{a}, 1}$, Ossi Rahkonen ${ }^{\mathrm{b}, 1}$, Eero Lahelma ${ }^{\mathrm{b}, 1}$, Jaana Pentti ${ }^{\mathrm{c}, 1}$, \\ Olli Pietiläinen $^{\text {b,1 }}{ }^{\text {, Jussi Vahtera }}{ }^{\text {d,e, }}$, Mika Kivimäki ${ }^{\text {a,b,f,1 }}$
}

a Finnish Institute of Occupational Health, Helsinki, Finland

${ }^{\mathrm{b}}$ Department of Public Health, University of Helsinki, Finland

c Finnish Institute of Occupational Health, Turku, Finland

${ }^{\mathrm{d}}$ Department of Public Health, University of Turku, Turku, Finland

e Turku University Hospital, Turku, Finland

${ }^{\mathrm{f}}$ Department of Epidemiology and Public Health, University College London, London, UK

\section{A R T I C L E I N F O}

\section{Article history:}

Received 15 July 2016

Received in revised form 23 December 2016

Accepted 25 December 2016

Available online 27 December 2016

\section{Keywords:}

Cardiovascular disease

Disability

Epidemiology

Prognosis

Socioeconomic factors

\begin{abstract}
A B S T R A C T
Background: Whether low occupational class amplifies the risk of disability retirement among employees with cardiovascular disease (CVD) is unknown. We examined this issue in two prospective cohort studies. Methods: In the Finnish Public Sector Study and the Helsinki Health Study ( $n=50.799$ employees), prevalent CVD (coronary heart disease or stroke, $n=1269$ ) was ascertained using records from national health registers, self-reported doctor-diagnosed diseases, and Rose Angina Questionnaire. Data linkage to national pension registers allowed the follow up of disability retirement among the participants for a mean of six years. We analysed the associations of occupational class and CVD with disability retirement using Cox regression, tested interactions between occupational class and prevalent CVD in predicting disability retirement by calculating the Synergy Index, and pooled the results from the two studies using fixed-effect meta-analysis.

Results: Compared with the participants from high occupational class and no CVD, the participants from the low occupational class without CVD had a 2.13-fold (95\% CI 1.97-2.30), those with high occupational class and CVD a 2.18-fold (1.73-2.74); and those with both low occupational class and CVD a 4.49-fold (3.83-5.26) risk of disability retirement. A Synergy Index of 1.55 (1.16-2.06) suggested a greater than additive effect for low occupational class and CVD in combination.

Conclusions: Individuals with both low occupational class and CVD are at a particularly high risk of premature exit from the labour market due to work disability. These findings suggest that better preventive strategies are needed to improve prognosis in this risk group.

(c) 2016 Elsevier Ireland Ltd. All rights reserved.
\end{abstract}

\section{Introduction}

The population is 'greying' in Europe; there were more than seven people of working age in 1950 to one out of labour force but due to increasing life expectancy and decreasing birth rate, the corresponding number will be fewer than two within the next 30 years [1]. There is a rapid decline in employment rates after age 55 , health problems playing a major role in early exits. For example, the proportion of individuals outside the labour market due to health reasons at age 60 is about a third of all economically inactive at that age [2]. Better understanding

\footnotetext{
* Corresponding author at: Finnish Institute of Occupational Health, P.O. Box 40, FI00251 Helsinki, Finland.

E-mail address: marianna.virtanen@ttl.fi (M. Virtanen).

1 This author takes responsibility for all aspects of the reliability and freedom from bias of the data presented and their discussed interpretation.
}

of factors predicting disability retirement is important for interventions and preventive policies.

Cardiovascular diseases (CVD), such as ischemic heart disease and cerebrovascular diseases, remain among the leading causes of years of life lost worldwide [3]. Their impact is not only on mortality but also on work disability, which may often persist for a long period of time or even become a permanent condition [4]. As the workforce is aging, CVD is not uncommon in working-age populations, and due to more effective treatments, many CVD patients remain in employment despite illnesses [5]. However, CVD is a major risk factor for premature exit from the labour market, as indicated by work disability retirement [6-10].

There is also established evidence on socioeconomic inequalities in morbidity and mortality, due to CVD in particular [11,12], with individuals from low socioeconomic groups having significantly higher disease rates than those from high socioeconomic groups [12]. In addition, 
recurrent events or death as adverse outcomes among CVD patients have shown to be more common among those with lower socioeconomic status [13]. In agreement with this, an inverse socioeconomic gradient has been observed in the risk of disability retirement $[14,15]$. However, we are not aware of studies that have examined whether this gradient is similar for people with and without CVD. Most of the research on this topic has focused on the short-term effect of socioeconomic status on return to work in a patient group (e.g., CVD) hospitalized or functionally disabled $[6,8,9]$. Knowing not only the risk factors but also combinations of risk factors is important for policies aiming at reducing socioeconomic inequalities in health and functional capacity among working populations.

In this study we used data from two large occupational cohorts to examine the associations of occupational class and prevalent CVD with subsequent disability retirement. We assessed the extent to which a combination of low occupational class and CVD affect the risk of disability retirement over and above their independent effects [16].

\section{Materials and methods}

\subsection{Populations and design}

We used data from two Finnish cohort studies, the Finnish Public Sector Study (FPS) [17] and the Helsinki Health Study (HHS) [18]. The FPS examines the employees of 10 Finnish municipalities and 21 hospitals. The base cohort consisted of FPS employees of all ages who responded to the survey in 2004 ( $n=48.076$ provided informed consent, response rate $66 \%$ ). Of these, 44,516 (93\%) were alive and not on disability pension at the beginning of follow-up (2005) and provided data on occupational class, CVD, and al covariates. The mean follow-up was $6.3(\mathrm{SD}=1.6)$ years. The FPS non-responders were slightly younger than the responders (mean age 45 versus 46 years), more often men ( $32 \%$ versus $20 \%$ ) and more often from lower occupational classes (46\% versus $43 \%$ ). The HHS examines municipal employees of the City of Helsinki, Finland. The baseline survey was mailed to employees who turned 40, 45, 50, 55, or 60 in 2000, 2001 and 2002. Altogether, 6605 responded to the baseline survey and provided informed consent (response rate $67 \%$ ). Of the responders, 6283 (95\%) were alive and not on disability pension at the beginning of follow-up (the year following the survey) and provided data on occupational class, CVD and all covariates. The mean follow-up was $6.2(\mathrm{SD}=1.7)$ years. The HHS nonresponders were slightly younger than the responders ( $46 \%$ aged $40-45$ versus $42 \%$ ), more often men (28\% versus $20 \%$ ) and more often from lower occupational classes (57\% versus $51 \%)[18]$

\subsection{Occupational class}

For both cohorts, occupational class was derived from the employers' personnel registers, and assigned to one of four categories based on job titles: Managers and professionals such as teachers and physicians; semi-professionals such as nurses and foremen; routine non-manual workers such as clerical employees and child minders; and manual workers such as technical and cleaning staff. Of these, managers, professionals and semiprofessionals were categorized into a high occupational class, and routine non-manual workers and manual workers into a low occupational class.

\subsection{Cardiovascular disease}

In the FPS, prevalent CVD included ischemic heart disease and cerebrovascular disease and those with CVD were defined as having at least one of the following: Special reimbursement for medication due to cardiac failure or coronary artery disease (from the register of the Social Insurance Institute of Finland); sickness absences or hospitalization with ICD-10 codes I20-I25, I46-I50, and I60-I69 between 2003 and 2004 (from the registers of the Social Insurance Institute of Finland and the National Institute of Health and Welfare) or a self-reported doctor-diagnosed cardiovascular disease (coronary thrombosis or angina) in the 2004 survey. The HHS defined prevalent CVD in a similar way, except that it included the Rose questionnaire $[19,20]$ in the survey to define prevalent angina at baseline, and did not include self-reported doctor-diagnosed coronary thrombosis.

\subsection{Work disability retirement}

Information on work disability retirement (the dates of granted disability pensions) was obtained for both cohorts from the Finnish Centre for Pensions, the official pension register in Finland, and was linked to the survey data. The participants were followed up for the incidence of disability pension for a maximum of seven years, starting from the beginning of the year following the survey year. In Finland, allowance for work disability pension can be granted after 300 days of sickness absence and this can be either fixedterm (usually for a year at a time), or permanent.

\subsection{Covariates}

In both cohorts, covariates were measured at the baseline and included sex and age, which were retrieved from employers' registers. In the FPS, other somatic disease included asthma, rheumatoid arthritis, cancer, and diabetes; information on which was derived from electronic medical records (cancer from the Finnish Cancer Registry, and the rest of the diseases from the Special Refund Entitlement Register of the Social Insurance Institute). The HHS included the same somatic diseases, but these were based on a check-list of self-reported doctor-diagnosed diseases. In both cohorts, common mental disorder was measured by a psychological distress scale, the 12-item General Health Questionnaire (GHQ-12) [21,22]. In the GHQ-12, respondents rate the extent to which they are affected by each of the 12 symptoms ( $1=$ not at all, $2=$ as much as usual, $3=$ slightly more than usual, $4=$ much more than usual). Participants with a rating of 3 or 4 in at least four items of the total measure were coded as cases of common mental disorder [23]. In both cohorts, obesity (body mass index $\geq 30 \mathrm{~kg} / \mathrm{m}^{2}$ ) and smoking (yes/no) were based on survey responses.

\subsection{Statistical analyses}

We used ANOVA and $\chi^{2}$ tests to assess differences between the baseline characteristics of participants with and without CVD, in both cohorts. We used Cox proportional hazard regression analysis to estimate hazard ratios (HR) and the $95 \% \mathrm{CI}$ for disability pension. Predictor variables were CVD, occupational class, and their combinations. Follow-up started at the beginning of the year following the survey year for both cohorts, and lasted a maximum of seven years, or until the awarding of work disability or old-age pension, or death, whichever occurred first. The status of CVD and occupational class were based on baseline information although there might have been some changes in these exposures during follow-up. Men and women were analysed together due to a relatively small number of men in both cohorts. The first model was adjusted for age and sex, and the second model for age, sex, other somatic disease, common mental disorder, obesity, and smoking. We calculated the Synergy Index (S) to examine whether the joint association of low occupational class and CVD deviated from their additive effect. This was done using the previously reported algorithm [16] in which $S=$ [HR (low occupational class and having CVD $)-1] /[(H R$ (high occupational class and CVD) -1$)+($ HR(low occupational class and no CVD) - 1)]. We used an Excel sheet provided by Andersson et al. [16] to calculate S and its 95\% confidence intervals (available at www.epinet.se). A Synergy Index of $1.0 \mathrm{im}-$ plies perfect additivity and $>1.0$ indicates that the joint effects of low occupational class and CVD on subsequent disability retirement are more than additive, i.e., more than one would assume by summing the two effects. To obtain a summary estimate across the two studies, the study-specific estimates were pooled using fixed-effect meta-analysis. We conducted $I^{2}$ statistics to assess the heterogeneity between the FPS and HHS estimates, which describes the percentage of variability in point estimates that is due to heterogeneity rather than sampling error [24]. All study-specific analyses were performed using SAS 9.4 statistical software, and meta-analyses were performed using Stata version 13.

\section{Results}

The mean age of the participants was $45.5(\mathrm{SD}=9.6)$ in the FPS and $49.2(\mathrm{SD}=6.5)$ in the HHS, and the proportion of women was $80.1 \%$ and $78.5 \%$, respectively. Prevalent CVD was ascertained in $878(2.0 \%)$ FPS participants and 391 (6.2\%) HHS participants (Table 1). Of the 878 FPS participants with CVD, $818(93.2 \%)$ had ischemic heart disease (IHD) only, 55 (6.3\%) had stroke only, and 5 (0.6\%) had both. Of the 391 HHS participants with CVD, 378 (96.7\%) had IHD only and 13 (3.3\%) had stroke only. Participants with prevalent CVD were older, more often men (in FPS), of lower occupational class, had more comorbid diseases and common mental disorders, and were more often obese than those free from CVD in both cohorts. No difference between the CVD cases' and non-cases' smoking was found in either cohort.

The associations between CVD and the incidence of work disability pension, and between occupational class and the incidence of work disability pension are shown in Online Online Supplemental Table 1, both for each cohort separately, and for the cohorts in combination. In the age- and sex-adjusted model, CVD was associated with an HR of 2.95 (95\% CI 2.55-3.41) for disability retirement in the FPS, and an HR of 2.28 (95\% CI 1.77-2.94) in the HHS. Adjustment for covariates attenuated this estimate to some extent (HRs 2.33 and 1.65). The pooled estimate for CVD associated with work disability pension was $\mathrm{HR}=2.14$ (95\% CI 1.88-2.43) in the multivariable adjusted model, although the association was stronger in the FPS cohort than in the HHS cohort $\left(I^{2}=\right.$ $80.6 \%, p=0.023$ ). Low occupational class was associated with disability retirement in both cohorts (multivariable adjusted $\mathrm{HR}=2.16,95 \% \mathrm{CI}$ $2.00-2.34$ in FPS; HR $=1.92,95 \%$ CI $1.58-2.33$ in HHS). The pooled 
estimate indicated an HR of 2.13 (95\% CI 1.98-2.29) between low occupational class and disability retirement, with little difference between the effect estimates of the studies $\left(I^{2}=17.7 \%, p=0.270\right)$.

The joint associations of occupational class and CVD with incident disability retirement are presented in Table 2 . In the FPS, low occupational class without CVD and high occupational class with CVD were associated with a similar risk of disability retirement (HRs 2.17 and 2.46, respectively in the multivariable adjusted model). A combination of low occupational class and CVD was associated with an amplified risk $(\mathrm{HR}=4.96)$, which was confirmed by a Synergy Index $(\mathrm{S}=1.51,95 \%$ CI 1.10-2.07). These findings were replicated in the HHS, except that the association for a combination of high occupational class and CVD tended to be smaller $(\mathrm{HR}=1.43)$ than that for low occupational class without CVD (1.87). Again, the joint association of low occupational class and CVD suggested synergy (HR $=3.27$ ), although the Synergy Index was not statistically significant $(\mathrm{S}=1.74,95 \% \mathrm{CI} 0.88-3.44)$.

Also shown in Table 2, pooled estimates in the multivariable adjusted model suggested an HR of 2.13 for disability retirement among participants with low occupational class without CVD, an HR of 2.18 among those with high occupational class and CVD, and an HR of 4.49 among those with a combination of low occupational class and CVD. The estimate was smaller in the HHS than that in the FPS $\left(\mathrm{I}^{2}=79.2 \%\right.$, $p=0.028$ ). The pooled Synergy Index was significant $(S=1.55,95 \%$ CI 1.16-2.06 in the multivariable adjusted model. We found no heterogeneity between study cohorts for the pooled Synergy Index $\left(\mathrm{I}^{2}=0.0 \%\right.$, $p=0.712$ ).

Fig. 1 demonstrates how events of disability retirement by a combination of low occupational class and CVD accumulate at an accelerating rate with age. The most pronouncing differences between groups are seen after the age 55 .

\section{Discussion}

In this prospective study of two large occupational cohorts, we examined the joint associations of low occupational class and prevalent CVD with the incidence of disability retirement, and demonstrated that low occupational class amplifies the adverse effect of CVD on disability retirement. A combination of low occupational class and prevalent CVD was associated with a 4.5 -fold increased risk of disability retirement when compared to individuals with high occupational class and no CVD. The corresponding hazard ratios of disability for low occupational class without CVD, and for CVD in high occupational class were both approximately two-fold.

Our findings of a two-fold independent risk of disability retirement associated with low occupational class and CVD confirms previous research that has reported associations of low socioeconomic status $[14,15]$ and CVD [6-10] with work disability. We found support for our hypothesis that low occupational class and CVD together might assert their influence on work disability pension over and above their independent effects. The reasons behind the amplifying effect of low occupational class might relate to the same universal mechanisms that generate inequalities in health across socioeconomic strata. These include access to care, which is a broad concept incorporating at least five different dimensions: Approachability, i.e., one's ability to identify health care services and the positive effects of their use on health; availability and accommodation, referring to physically available health care services; affordability, i.e. one's economic capacity to spend resources and time on health care; and acceptability, which refers to the sociocultural factors that shape people's perception of health care and their appropriateness [25]. There is evidence of poorer adherence to treatment and monitoring of chronic diseases among people with low socioeconomic status [26] although not confirmed in our data with adherence to statin therapy as an outcome [27]. Unfortunately, in our data we had no detailed information on health service use associated with CVD or different aspects of access to care, although in Finland universal health care is available to all citizens. However, in Finland, there is a parallel health care system of private services which are more commonly used by affluent people with high socioeconomic positions [28]. As a consequence, these services have differential access according to socioeconomic status. There is also evidence of socioeconomic inequity in deaths amenable to health care interventions in Finland [29].

The second pathway potentially explaining why low occupational class might amplify the risk of disability retirement among individuals with CVD involves health risk behaviours such as smoking, obesity and an unhealthy diet $[25,30]$. In our study, the associations persisted after adjustment for smoking and obesity, and there was little difference between the smoking prevalence of CVD cases and non-cases in the cohorts studied. It is well-known that smoking is strongly associated with the incidence of CVD [31]. Smoking cessation is common after the onset of CVD [32] although less common among people with low income [26].

Table 1

Characteristics of participants by prevalent cardiovascular disease (CVD) at baseline in Finnish Public Sector Study and Helsinki Health Study.

\begin{tabular}{|c|c|c|c|c|c|c|c|c|}
\hline \multirow{3}{*}{ Characteristics } & \multicolumn{4}{|c|}{ Finnish Public Sector Study } & \multicolumn{4}{|c|}{ Helsinki Health Study } \\
\hline & \multicolumn{4}{|l|}{ Prevalent CVD } & \multicolumn{4}{|l|}{ Prevalent CVD } \\
\hline & All $(n=44.516)$ & No $(n=43.638)$ & Yes $(n=878)$ & $\mathrm{p}^{*}$ & All $(n=6283)$ & No $(n=5892)$ & Yes $(n=391)$ & $\mathrm{p}^{*}$ \\
\hline \multicolumn{9}{|l|}{ Age } \\
\hline Mean (SD) & $45.5(9.6)$ & $45.3(9.6)$ & $53.0(7.0)$ & $<0.001$ & $49.2(6.5)$ & $49.0(6.5)$ & $51.7(6.2)$ & $<0.001$ \\
\hline \multicolumn{9}{|l|}{ Sex } \\
\hline Male & 8858 (19.9) & 8553 (19.6) & $305(34.7)$ & \multirow[t]{2}{*}{$<0.001$} & $1352(21.5)$ & 1269 (21.5) & $83(21.2)$ & \multirow[t]{2}{*}{0.89} \\
\hline Female & $35,658(80.1)$ & $35,085(80.4)$ & $573(65.3)$ & & $4931(78.5)$ & $4623(78.5)$ & $308(78.8)$ & \\
\hline \multicolumn{9}{|c|}{ Occupational class } \\
\hline High & $25,706(57.8)$ & $25,297(58.0)$ & $409(46.6)$ & \multirow[t]{2}{*}{$<0.001$} & $3229(51.4)$ & 3069 (52.1) & $160(40.9)$ & \multirow[t]{2}{*}{$<0.001$} \\
\hline Low & $18,810(42.3)$ & $18,341(42.0)$ & $469(53.4)$ & & $3054(48.6)$ & $2823(47.9)$ & $231(59.1)$ & \\
\hline \multicolumn{9}{|c|}{ Other somatic disease } \\
\hline No & $40,515(91.0)$ & $39,852(91.3)$ & $663(75.5)$ & \multirow[t]{2}{*}{$<0.001$} & 5395 (85.9) & 5107 (86.7) & $288(73.7)$ & \multirow[t]{2}{*}{$<0.001$} \\
\hline Yes & $4001(9.0)$ & $3786(8.7)$ & $215(24.5)$ & & $888(14.1)$ & $785(13.3)$ & $103(26.3)$ & \\
\hline \multicolumn{9}{|c|}{ Common mental disorder } \\
\hline No & $33,621(75.5)$ & $33,059(75.8)$ & $562(64.0)$ & \multirow[t]{2}{*}{$<0.001$} & $5036(80.2)$ & $4782(81.2)$ & $254(65.0)$ & \multirow[t]{2}{*}{$<0.001$} \\
\hline Yes & $10,895(24.5)$ & $10,579(24.2)$ & $316(36.0)$ & & 1247 (19.9) & $1110(18.8)$ & $137(35.0)$ & \\
\hline \multicolumn{9}{|l|}{ Obesity } \\
\hline No & $38,771(87.1)$ & $38,079(87.3)$ & $692(78.8)$ & \multirow{2}{*}{$<0.001$} & $5373(85.5)$ & $5094(86.5)$ & $279(71.4)$ & \multirow[t]{2}{*}{$<0.001$} \\
\hline Yes & $5745(12.9)$ & $5559(12.7)$ & $186(21.2)$ & & $910(14.5)$ & $798(13.5)$ & $112(28.6)$ & \\
\hline \multicolumn{9}{|l|}{ Smoking } \\
\hline No & $36,898(82.9)$ & 36,165 (82.9) & $733(83.5)$ & \multirow[t]{2}{*}{0.63} & $4842(77.1)$ & $4550(77.2)$ & $292(74.7)$ & \multirow[t]{2}{*}{0.25} \\
\hline Yes & $7618(17.1)$ & $7473(17.1)$ & $145(16.5)$ & & $1441(22.9)$ & $1342(22.8)$ & $99(25.3)$ & \\
\hline
\end{tabular}

$\mathrm{SD}=$ standard deviation. Figures are $\mathrm{n}(\%)$ unless otherwise stated.

* $P$ values for difference between participants with and without CVD, based on Anova and $\chi^{2}$ tests. 
Table 2

Joint association of cardiovascular disease (CVD) and occupational class with subsequent work disability retirement in Finnish Public Sector Study and Helsinki Health Study.

\begin{tabular}{|c|c|c|c|c|}
\hline CVD and occupational class & No. of events & Retirement rate/1000 person-years & HR (95\% CI) Model 1 ${ }^{\mathrm{a}}$ & HR (95\% CI) Model $2^{\text {b }}$ \\
\hline \multicolumn{5}{|l|}{ Finnish Public Sector Study } \\
\hline No CVD - high occupational class & 912 & 5.59 & 1.00 & 1.00 \\
\hline No CVD - low occupational class & 1711 & 14.98 & $2.30(2.13-2.50)$ & $2.17(2.00-2.36)$ \\
\hline CVD - high occupational class & 61 & 29.19 & $2.98(2.29-3.86)$ & $2.46(1.89-3.19)$ \\
\hline CVD - low occupational class & 138 & 62.82 & $6.36(5.31-7.62)$ & $4.96(4.14-5.96)$ \\
\hline Synergy Index (S) & & & $1.63(1.21-2.22)$ & $1.51(1.10-2.07)$ \\
\hline \multicolumn{5}{|l|}{ Helsinki Health Study } \\
\hline No CVD - high occupational class & 148 & 7.67 & 1.00 & 1.00 \\
\hline No CVD - low occupational class & 273 & 15.70 & $2.03(1.66-2.49)$ & $1.87(1.52-2.30)$ \\
\hline CVD - high occupational class & 19 & 22.27 & $2.05(1.27-3.32)$ & $1.43(0.88-2.32)$ \\
\hline CVD - low occupational class & 52 & 40.88 & $4.47(3.25-6.16)$ & $3.27(2.36-4.52)$ \\
\hline \multirow[t]{3}{*}{ Synergy Index (S) } & & & 1.66 (0.92-2.99) & $1.74(0.88-3.44)$ \\
\hline & \multicolumn{4}{|l|}{ Pooled estimates } \\
\hline & $I^{2}$ heterogeneity ( $p$-value $)^{\mathrm{a}}$ & $I^{2}$ heterogeneity ( $p$-value $)^{\mathrm{b}}$ & HR $(95 \% \mathrm{CI})$ Model $1^{\mathrm{a}}$ & HR $\left(95 \%\right.$ CI) Model $2^{b}$ \\
\hline No CVD - high occupational class & & & 1.00 & 1.00 \\
\hline No CVD - low occupational class & $20.7 \%(0.262)$ & $41.5 \%(0.191)$ & $2.26(2.10-2.44)$ & $2.13(1.97-2.30)$ \\
\hline CVD - high occupational class & $44.4 \%(0.180)$ & $73.2 \%(0.054)$ & $2.74(2.18-3.44)$ & $2.18(1.73-2.74)$ \\
\hline CVD - low occupational class & $71.8 \%(0.060)$ & $79.2 \%(0.028)$ & $5.84(5.00-6.83)$ & $4.49(3.83-5.26)$ \\
\hline Synergy Index (S) & $0.0 \%(0.957)$ & $0.0 \%(0.712)$ & $1.64(1.25-2.14)$ & $1.55(1.16-2.06)$ \\
\hline
\end{tabular}

$\mathrm{HR}=$ hazard ratio; $\mathrm{CI}=$ confidence interval.

a Adjusted for age and sex.

b Adjusted for age, sex, other somatic disease, common mental disorder, obesity, and smoking.

Our findings support the notion that the prevention of adverse outcomes, such as premature exit from the labour market due to health reasons by simply targeting unhealthy behaviours at the individual level, might be an insufficient agenda, although an unhealthy lifestyle is socially patterned, i.e., affected by the socioeconomic circumstances in which people live [25].

It is also possible that the people in our study from a low occupational class had more severe CVD than those from a high occupational class. This hypothesis has been supported by a Finnish study that reported an increased risk of major adverse cardiac events, coronary mortality and re-revascularization after coronary revascularizations among coronary patients with a low socioeconomic status [33].

Furthermore, as working capacity concerns health status on the one hand, and the demands of work on the other hand, work disability schemes in many countries, including Finland, are based on judgments of an interplay between an individual's health resources and work demands [30]. Both health status (i.e., more severe disease) and work demands (i.e., more physically or psychosocially strenuous work) may lie behind their higher risk of disability retirement among people from a low occupational class when they have a CVD.

\subsection{Strengths and limitations}

The specific strengths of this study include its large cohort sizes and prospective study design with a long follow-up, and its objective measures of occupational class and work disability pension retrieved from liable national registers and employers' records. Several limitations are noteworthy. Although we controlled for several covariates in our datasets, some unobserved variables might partly explain the observed associations. We dichotomised the occupational groups in 'high' and 'low' according to the occupational hierarchy. In the future, larger studies allowing analysis of specific occupational groups are needed to obtain a more detailed analysis of occupational class differences in disability retirement among CVD cases.

Although the pattern of findings was the same across the two cohort studies and no heterogeneity was observed in the Synergy Index,
(A) Finnish Public Sector Study

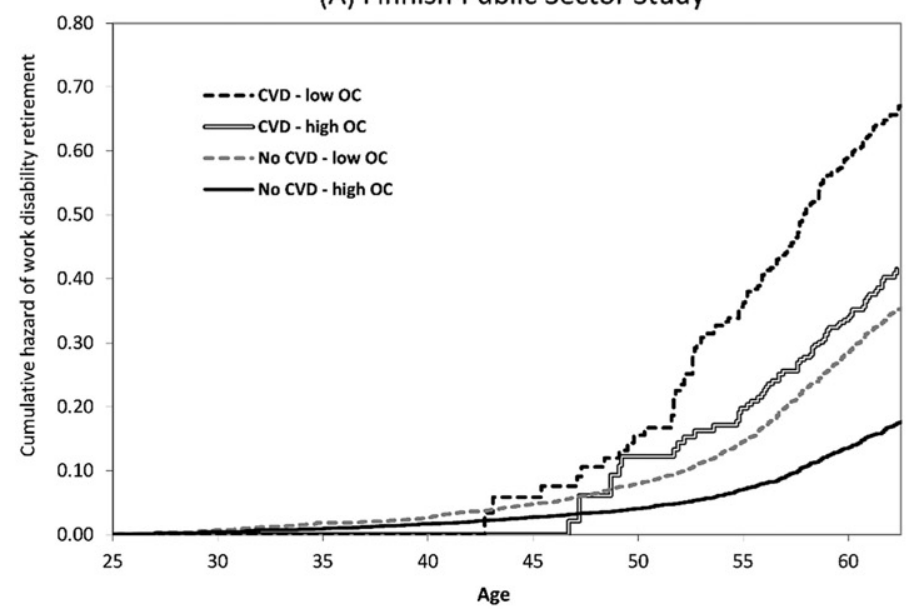

(B) Helsinki Health Study

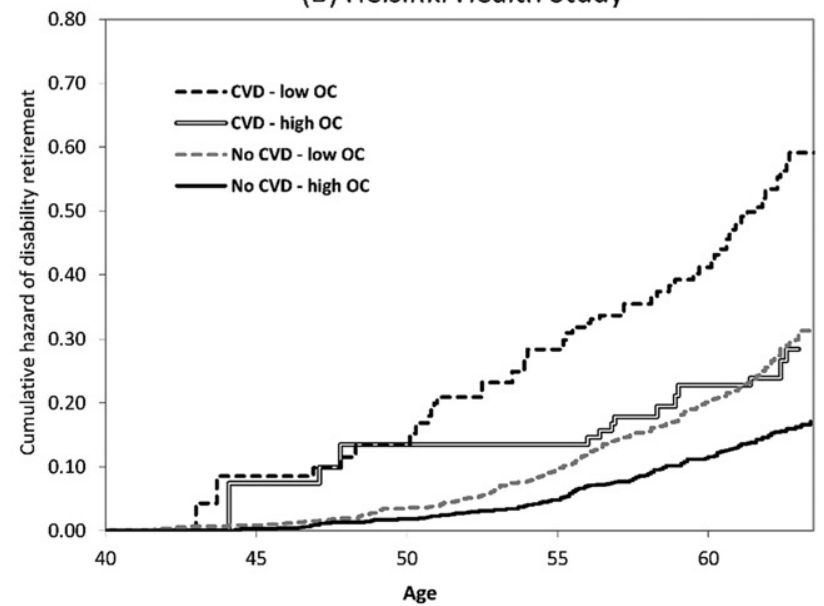

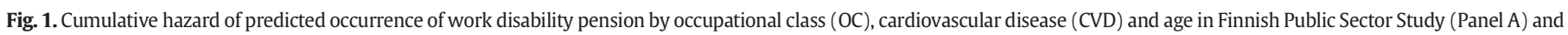
Helsinki Health Study (Panel B). 
heterogeneity was found in the study-specific association between CVD and disability retirement; the association was stronger in FPS than HHS. Although both populations were public sector employees, HHS participants were older, which may contribute to the observed heterogeneity. In addition, the vast majority of CVD cases (83\%) in HHS was identified using the Rose Angina Questionnaire which was not available in FPS in which $36 \%$ of the cases were based on self-reported doctor-diagnosed CVD. The questionnaire identifies potential undetected angina cases, thus making the case definition different in the two cohorts. However, the Rose Questionnaire is considered a valid screening instrument for heart disease in epidemiological studies [34] as well as in the HHS study [20]. The validity of prevalent self-reported doctor-diagnosed coronary heart disease has been shown to be satisfactory in FPS data [35]. However, further research with several cohorts is needed to detect the sources of heterogeneity in detail.

Furthermore, public sector employees comprise predominantly women, thus, sex-specific analyses were not possible to carry out. The responders represented about $2 / 3$ of the eligible population and women, older employees and those in higher occupational classes were more likely to respond in both cohorts. However, the responders' sex distribution (about 80\% women) corresponds to that among the total Finnish municipal sector ( $80 \%$ women) although we acknowledge that non-response is a potential source of bias, more so among men. Nevertheless, overall such bias is unlikely to substantially distort results concerning relative risks of health, and a detailed non-response analysis on HHS cohort suggested that survey non-response did not seriously bias the findings on socioeconomic inequalities in health [36]. Data on race/ethnicity and social support in private life [25] were not available. However, it is known from a record sample that the study cohorts are approximately 95\% Finnish-born and our previous study has shown that social support is an unlikely mechanism explaining the social class differences in work disability [37].

Finally, these data represent the Finnish municipal sector organisations. Although the spectrum of jobs covers a large number of nonmanual and manual occupations, the cohorts were not representative of the Finnish working population. Compared to the rest of Europe, educational attainment in Finland is high, particularly among younger age groups, which may further limit the generalisability of our findings to other countries [38].

\section{Conclusions}

The risk of work disability retirement among people with CVD is amplified by low occupational class, so that employees with low occupational class and CVD are at a particularly high risk of premature exit from the labour market due to disability. These findings suggest that low socioeconomic status should be taken into considerations as a risk factor for poor labour market outcomes in CVD. The mechanisms of the observed association are not known and require further investigation. Future research should also examine whether specific support targeted at employees with CVD and low occupational class is beneficial in terms of prevention of premature exit from the labour market due to work disability.

Supplementary data to this article can be found online at http://dx. doi.org/10.1016/j.ijcard.2016.12.166.

\section{Grant support}

The Helsinki Health Study was supported by the Academy of Finland (\#1129225, \#1257362, \#1294514) and the Finnish Work Environment Fund (\#112231). Dr Virtanen, Dr Lallukka, and Dr Ervasti were supported by the Academy of Finland (projects 258598, 292824, 287488, \#294096), Dr Vahtera was supported by the Era-Age2 grant (Academy of Finland \#264944), Dr Kivimäki was supported by the UK Medical Research Council (K013351), the Economic and Social Research Council and NordForsk (the Research Programme for Health and Welfare).

\section{Conflict of interest}

None declared.

\section{References}

[1] A.C. D'Addio, F. Von Nordheim, Towards an integrated agenda to deliver effective higher retirement ages: an issues note from the pension perspective, Workshops on Delivering Longer Working Lives and Higher Retirement Ages, Brussels 12th13th November 2014, OECD, 2014

[2] European Commission, Directorate-general for Employment, Social Affairs and Equal Opportunities. Longer Working Lives through Pension Reforms, European Communities, Luxembourg, 2009.

[3] Global Burden of Diseases Study Group, Global, regional, and national age-sex specific all-cause and cause-specific mortality for 240 causes of death, 1990-2013: a systematic analysis for the Global Burden of Disease Study 2013, Lancet 385 (2015) 117-171.

[4] B. Norrving, B. Kissela, The global burden of stroke and need for a continuum of care, Neurology 80 (2013) S5-12.

[5] K. Zetterstrom, M. Voss, K. Alexanderson, T. Ivert, K. Pehrsson, N. Hammar, et al. Prevalence of all-cause and diagnosis-specific disability pension at the time of first coronary revascularisation: a population-based Swedish cross-sectional study, PLoS One 10 (2015), e0115540.

[6] J. Perk, K. Alexanderson, Swedish Council on Technology Assessment in Health Care (SBU). Chapter 8. Sick leave due to coronary artery disease or stroke, Scand. J. Public Health Suppl. 63 (2004) 181-206.

[7] H. Hemingway, J. Vahtera, M. Virtanen, J. Pentti, M. Kivimäki, Outcome of stable angina in a working population: the burden of sickness absence, Eur. J. Cardiovasc. Prev. Rehabil. 14 (2007) 373-379.

[8] L. Chaker, A. Falla, S.J. van der Lee, T. Muka, D. Imo, L. Jaspers, et al., The global impact of non-communicable diseases on macro-economic productivity: a systematic review, Eur. J. Epidemiol. 30 (2015) 357-395.

[9] M. Osler, S. Martensson, E. Prescott, K. Carlsen, Impact of gender, co-morbidity and social factors on labour market affiliation after first admission for acute coronary syndrome. A cohort study of Danish patients 2001-2009, PLoS One 9 (2014), e86758.

[10] J. Ervasti, M. Kivimäki, J. Pentti, P. Salo, T. Oksanen, J. Vahtera, et al., Health- and work-related predictors of work disability among employees with a cardiometabolic disease - a cohort study, J. Psychosom. Res. 82 (2016) 41-47.

[11] A.M. Clark, M. DesMeules, W. Luo, A.S. Duncan, A. Wielgosz, Socioeconomic status and cardiovascular disease: risks and implications for care, Nat. Rev. Cardiol. 6 (2009) 712-722.

[12] M. Di Cesare, Y.H. Khang, P. Asaria, T. Blakely, M.J. Cowan, F. Farzadfar, et al., Inequalities in non-communicable diseases and effective responses, Lancet 381 (2013) 585-597.

[13] S. Rashid, A. Simms, P. Batin, J. Kurian, C.P. Gale, Inequalities in care in patients with acute myocardial infarction, World J. Cardiol. 7 (2015) 895-901.

[14] S. Krokstad, R. Johnsen, S. Westin, Social determinants of disability pension: a 10year follow-up of 62000 people in a Norwegian county population, Int. J. Epidemiol. 31 (2002) 1183-1191.

[15] A. Polvinen, M. Laaksonen, R. Gould, E. Lahelma, P. Martikainen, The contribution of major diagnostic causes to socioeconomic differences in disability retirement, Scand. J. Work Environ. Health 40 (2014) 353-360.

[16] T. Andersson, L. Alfredsson, H. Kallberg, S. Zdravkovic, A. Ahlbom, Calculating measures of biological interaction, Eur. J. Epidemiol. 20 (2005) 575-579.

[17] M. Kivimäki, D.A. Lawlor, G. Davey Smith, A. Kouvonen, M. Virtanen, M. Elovainio et al., Socioeconomic position, co-occurrence of behavior-related risk factors, and coronary heart disease: the Finnish Public Sector study, Am. J. Public Health 97 (2007) 874-879.

[18] E. Lahelma, A. Aittomäki, M. Laaksonen, T. Lallukka, P. Martikainen, K. Piha, et al., Cohort profile: the Helsinki Health Study, Int. J. Epidemiol. 42 (2013) 722-730.

[19] G.A. Rose, Ischemic heart disease. Chest pain questionnaire, Milbank Mem. Fund 43 (1965) 32-39.

[20] T. Lallukka, K. Manderbacka, I. Keskimaki, H. Hemingway, O. Rahkonen, E. Lahelma, et al., Angina pectoris: relation of epidemiological survey to registry data, Eur. J. Cardiovasc. Prev. Rehabil. 18 (2011) 621-626.

[21] D.P. Goldberg, The Detection of Psychiatric Illness by Questionnaire, Oxford University Press, London, 1972.

[22] D.P. Goldberg, R. Gater, N. Sartorius, T.B. Ustun, M. Piccinelli, O. Gureje, et al., The validity of two versions of the GHQ in the WHO study of mental illness in general health care, Psychol. Med. 27 (1997) 191-197.

[23] M.M. Holi, M. Marttunen, V. Aalberg, Comparison of the GHQ-36, the GHQ-12 and the SCL-90 as psychiatric screening instruments in the Finnish population, Nord. J. Psychiatry 57 (2003) 233-238.

[24] J.P.T. Higgins, S.G. Thompson, Quantifying heterogeneity in a meta-analysis, Stat. Med. 21 (2002) 1539-1558.

[25] E.P. Havranek, M.S. Mujahid, D.A. Barr, I.V. Blair, M.S. Cohen, S. Cruz-Flores, et al Social determinants of risk and outcomes for cardiovascular disease: a scientific statement from the American Heart Association, Circulation 132 (2015) 873-898.

[26] D.J. Campbell, P.E. Ronksley, B.J. Manns, M. Tonelli, C. Sanmartin, R.G. Weaver, et al., The association of income with health behavior change and disease monitoring among patients with chronic disease, PLoS One 9 (2014), e94007.

[27] M.J. Korhonen, J. Pentti, J. Hartikainen, M. Kivimäki, J. Vahtera, Somatic symptoms of anxiety and nonadherence to statin therapy, Int. J. Cardiol. 214 (2016) 493-499. 
[28] M. Kajantie, Lääkäripalvelujen käyttö Jakaa väestöä [Use of Medical Services Divides the Population, in Finnish], Statistics Finland, Hyvinvointikatsaus, 2014.

[29] S. Lumme, R. Sund, A.H. Leyland, I. Keskimäki, Socioeconomic equity in amenable mortality in Finland 1992-2008, Soc. Sci. Med. 75 (2012) 905-913.

[30] E. Lahelma, H. Uusitalo, P. Martikainen, Longer work careers through tackling socioeconomic inequalities in disability retirement, Eur. J. Pub. Health 22 (2012) 299-300.

[31] G.A. Roth, G. Nguyen, M.H. Forouzanfar, A.H. Mokdad, M. Naghavi, C.J. Murray, Estimates of global and regional premature cardiovascular mortality in 2025 Circulation 132 (2015) 1270-1282.

[32] M.A. Rahman, K.L. Edward, L. Montgomery, S. McEvedy, A. Wilson, L. Worrall-Carter, Is there any gender difference for smoking persistence or relapse following diagnosis or hospitalization for coronary heart disease? Evidence from a systematic review and meta-analysis, Nicotine Tob. Res. 18 (2016) 1399-1407.

[33] K. Manderbacka, M. Arffman, S. Lumme, I. Keskimäki, Are there socioeconomic differences in outcomes of coronary revascularizations-a register-based cohort study, Eur. J. Pub. Health 25 (2015) 984-989.
[34] P.D. Sorlie, L. Cooper, P.J. Schreiner, W. Rosamond, M. Szklo, Repeatability and validity of the rose questionnaire for angina pectoris in the Atherosclerosis Risk in Communities Study, J. Clin. Epidemiol. 49 (1996) 719-725.

[35] T. Oksanen, M. Kivimäki, J. Pentti, M. Virtanen, T. Klaukka, J. Vahtera, Self-report as an indicator of incident disease, Ann. Epidemiol. 20 (2010) 547-554.

[36] P. Martikainen, M. Laaksonen, K. Piha, T. Lallukka, Does survey non-response bias the association between occupational social class and health? Scand. J. Public Health 35 (2007) 212-215

[37] M. Laaksonen, K. Piha, O. Rahkonen, P. Martikainen, E. Lahelma, Explaining occupational class differences in sickness absence: results from middle-aged municipal employees, J. Epidemiol. Community Health 64 (2010) 802-807.

[38] Eurostat, Educational Attainment Statistics, European Commission, 2016 http:// ec.europa.eu/eurostat/statistics-explained/index.php/Educational_attainment_ statistics. 